\title{
IDENTIFYING THE OPTIMAL BODY SHAPE AND COMPOSITION ASSOCIATED WITH STRENGTH OUTCOMES IN CHILDREN AND ADOLESCENT ACCORDING TO PLACE OF RESIDENCE: AN ALLOMETRIC APPROACH
}

Nicola Lovecchio ${ }^{1,2}$, Matteo Giuriato ${ }^{3}$, Matteo Zago $^{4,5}$, Alan Nevill ${ }^{6}$

Running title: allometric approach to strength outcomes

Key words: allometric, children, adolescent, strength test, body mass, place of residence

\footnotetext{
${ }^{1}$ Departement of Biomedical Science for Health, Università degli Studi di Milano, Milano, Italy

${ }^{2}$ Laboratory of Adapted Motor Activity (LAMA), Department of Public Health, Experimental and Forensic Medicine, University of Pavia, Pavia, Italy

${ }^{3 *}$ Department of Human Science, Università degli Studi di Verona, Lungadige Porta Vittoria, 17, 37129 Verona, Italy; e-mail: matteo.giuriato@univr.it; mob: +39 3408900701

${ }^{4}$ Movement and Posture Analysis Lab, Politecnico di Milano, Italy

${ }^{5}$ Fondazione Istituto Farmacologico Filippo Serpero, Viale Luigi Majno 40, 20122, Milano, Italy

${ }^{6}$ Institute of Sport \& Human Sciences, University of Wolverhampton, Wolverhampton, UK.

* corresponding author
}

All authors no conflicts of interest and no sources of funding are declared 


\title{
IDENTIFYING THE OPTIMAL BODY SHAPE AND COMPOSITION ASSOCIATED WITH STRENGTH OUTCOMES IN CHILDREN AND ADOLESCENT ACCORDING TO PLACE OF RESIDENCE: AN ALLOMETRIC APPROACH
}

\begin{abstract}
The purpose of the study was to identify the optimal body shape and composition associated with physical fitness levels of children living in urban and rural areas of Italy. A total of 7102 children (11-14 years) were assessed for weight, height, percentage body fat (FM\%), sit-and-reach flexibility (SAR), standing broad jump (SBJ) and sit-ups (SUP). A multiplicative allometric model, $\mathrm{Y}=\mathrm{a} \cdot \mathrm{mass}^{\mathrm{k}_{1}} \cdot$ height $^{\mathrm{k}_{2}}$ - $\varepsilon$, was used to predict the physical outcome variables $\mathrm{Y}=\mathrm{SBJ}$ and SUP. The model was expanded to incorporate $\mathrm{FM} \%$ and SAR as follows $\mathrm{Y}=\mathrm{a} \cdot \mathrm{mass}^{\mathrm{k}_{1}} \cdot \mathrm{height}^{\mathrm{k}_{2}} \cdot \mathrm{FM} \%{ }^{\mathrm{k}_{3}} \cdot \exp (\mathrm{b} \cdot \mathrm{FM} \%+\mathrm{c} \cdot \mathrm{SAR}) \cdot \varepsilon$. Note that $\mathrm{FM} \%$ was incorporated as a 'gamma function' that allows an initial growth, and subsequent decline in $\mathrm{Y}$ as FM\% increases in size. Although having an ectomorph body shape appears advantageous, being too thin appears detrimental to the strength outcomes. Being flexible would also benefit physical fitness levels. Finally, our results indicate that urban children aged 11 to 14 have superior strength outcomes compared with rural children, having controlled for differences in body shape and composition, a finding that may be associated with rural environments having fewer exercise facilities compared with urban conurbations.
\end{abstract}




\section{Introduction}

Physical fitness outcomes are affected by large variations during growth (Lloyd, Oliver, Faigenbaum, Myer \& De Ste Croix, 2014). One of the most important body shape indices associated with fitness, at least during childhood, is the ponderal index (Bjerregaard et al., 2014; Smith, Montaño, Dishion, Shaw \& Wilson, 2015). The association between physical fitness level and the ponderal index remains controversial, however. Physical fitness involves several different components, including muscular strength, flexibility, motor skill coordination (Vandorpe et al., 2011), speed agility and endurance capacity (the cardiorespiratory tests are the most administrated test to define the physical efficiency; Bouchard, Shephard \& Stephens, 2011; Deforche et al., 2003). Furthermore, Lovecchio \& Zago (2018) recently demonstrated equal results (Sit and Reach, Standing Broad Jump, Shuttle Run Test 5mx 10, Sit ups) for young children in different body-mass index ([BMI] weight in kg divided by height in meters squared) categories. Given the general growth path and the fluctuations across different BMI categories during childhood (Cole, Bellizzi, Flegal \& Dietz, 2000; Cole, Flegal, Nicholls \& Jackson, 2007), allometric analysis has been proposed as the most robust approach to evaluate physical outcomes during growth (Bustamante Valdivia, Maia \& Nevill 2015; Dos Santos et al., 2018; Nevill \& Holder, 1985,2000; Silva et al., 2016).

Moreover, analysis of physical fitness in young people should also take into account the individual's social and environmental context. Differences in eating habits, access to sport facilities, and opportunities for physical fitness activities can depend on the population density of an area (rural/urban context; Carlson et al., 2014; Malina, Peña Reyes \& Little, 2008). Malina et al. (2008) found higher levels of physical activities (MET intensity; Ainsworth et al., 2000) in urban young people due to the availability of sport facilities and to their higher Socio-Economic-Status. In contrast, increased sedentary lifestyles and lower levels of physical activity were reported for urban residents (Seefeldt, Malina \& Clark, 2009). More recently, no significant differences between rural and urban communities were found in terms of the amount of metres walked, perception of self-efficacy, heart rate and intensity of physical activity (Carlson et al., 2014; Collins, Al-Nakeeb, Nevill, \& Lyons, 2012), particularly when the assessment excluded cardio-fitness trials (Lovecchio, Novak, Eid, Casolo \& Podnar, 2015).

Despite these inconsistencies, the rural-urban differential is an important macro-factor that influences participation in physical activity (Tsimeas, Tsiokanos, Koutedakis, Tsigilis \& Kellis, 2005) and cannot be dissociated from general growth (Vandorpe et al., 2011). Hence the aim of this study was to compare 
physical fitness levels in children living in urban and rural areas using allometric scaling to obtain the optimal body shape and body composition associated with such weight-baring physical activities.

\section{MATERIALS AND METHODS}

\section{Participants}

A total of 7102 junior high school children (3058 boys; 4044 girls) aged 11-14 years living in an urban or rural area of norther Italy volunteered to participate in the study. The children were assessed for weight, height, percentage body fat (estimated using skinfold thickness, see below) and physical fitness level. Inclusion criteria were: no history of illness potentially affecting growth; no neurological, orthopedic or cardiovascular diseases; active participation in physical education (PE) classes. Children found in good general health were deemed eligible. The parents (or legal guardians) gave written, informed consent after having received a detailed explanation of the study procedure and possible risks. Children gave their verbal consent and were informed that involvement in the study could be interrupted at any time. The study was conducted in accordance with the Declaration of Helsinki (as revised in 1983) and after approval of the regional office of Ministry of Education (drlo-09-1516; Prot. EF-230). All data were collected during PE classes. The mean (SD) anthropometric characteristics of the children by sex and place of residence (urban or rural) are given in Table 1.

****Table 1 near here****

\section{Anthropometric characteristics}

Anthropometric measurements of height and weight were taken according to standard procedures described by the International Society for the Advancement of Kinanthropometry (Clarys, Provyn, Marfell-Jones \& Van Ro, 2006). Height was measured with a stadiometer to the nearest 0.1 centimeter (cm) with participants barefoot standing in an upright position with the head in the Frankfort plane. Weight was measured to the nearest 0.1 kilogram $(\mathrm{kg})$ with an electronic scale with participants wearing minimal clothing, BMI was then calculated.

The percentage of FM (FM\%) was estimated using skinfolds (known to be associated with body fatness in young people; Duren et al, 2008; Boeke et al, 2013). Skinfold thickness were measured in triplicate to the nearest $0.1 \mathrm{~cm}$ at the triceps and subscapular crest (Heymsfield et al., 2005) with Harpenden calipers (HSK-BI, British Indicators, Weybridge, UK). The percentage of FM (FM\%) was then determined using the formula proposed by Blaha \& Vignerova (2002) and Carter (2002): 
Boys FM $\%=0.735 \mathrm{x}$ (triceps skinfold + subscapularis skinfold $)+1$

Girls FM \% = 0.61 x (triceps skinfold + subscapularis skinfold $)+5.1$

\section{Place of residence}

The classification of urban and rural was based on the criteria suggested by Pokos (2002) and Tsimeas, et al. (2005) as indicated by the United Nation (2002): towns with a population of 10.000 or more were classified as urban. towns with less than 10.000 was classified as rural. In particular, the rural area (including three Region in North Italy) was the Pianura Padana: an area characterized by agricultural cooperative society farms and woods. The urban area was represented by the metropolitan district of Milano city: the richest and most developed city in Italy (C.I.A., 2011).

\section{Physical fitness tests}

Three tests were selected from a reliable and valid battery of physical fitness tests (Council of Europe, 1998; Kemper \& Van Mechelen, 1996; Ruiz et al, 2011; Tomkinson, Olds \& Borms, 2007): standing broad jump (SBJ), sit-ups (SUP) and sit and reach (SAR) were performed to define explosive strength, the endurance strength and flexibility of the hamstring and the spine muscles; respectively. In particular, the three fitness tests (from the Eurofit Battery) were selected because their results are considered independent (Castro-Piñero et al, 2010; Lovecchio, Casolo, Invernizzi \& Eid, 2012), free of instructor influence, simple to administrate, inexpensive and easy to organize in the school setting (Huotari, Nupponen, Laakso, \& Kujala, 2010; Kemper \& Van Mechelen, 1996; Tomkinson et al, 2007, 2017). A brief explanation is reported below (Council of Europe., 1998).

Standing broad jump (SBJ): Each participant performed distance jumps from a standing start (systematic error nearly to 0; Ortega et al., 2008). While performing the jumps, the Participants were asked to bend their knees with their arms in front of them, parallel to the ground, then to swing both arms, push off vigorously and jump forward as far as possible, trying to land with their feet together and stay upright. The best out of two attempts was taken as the final score (expressed in centimeters).

Sit-ups: The maximum number of sit-ups achieved in $30 \mathrm{~s}$ (SU30) was recorded (ICC values ranged from 0.85 to 0.98 ; Artero et al., 2011). The subjects were instructed to keep their fingers interlocked behind the head while curling up to a sitting position until their body was vertical, then return to the floor. This test assesses abdominal endurance strength. One trial was evaluated. 
Sit and reach $(S A R)$ : The European protocol of SAR test requires a box which has a scale marked out on the upper side (ICC $=0.98$; Bozic et al., 2010). The subject sits on the floor with his both knees extended and the feet placed flat against the device (referencing at zero). The subject is then asked to reach slowly forward over the measuring device with both hands as far as possible and hold this position for 2 seconds.

\section{Statistical Methods}

The multiplicative model (Eq.1) with allometric body-size components was used to identify the most appropriate body size and shape characteristics associated with, as well as detect any categorical differences (e.g., sex, age, place of residence urban vs. rural) in, two physical performance variables (SBJ and the number of sit-ups performed in $30 \mathrm{~s}$ (SUP). The model is similar to that used to predict the physical performance variables of Greek children (Nevill, Tsiotra, Tsimeas \& Koutedakis, 2009).

$$
\mathrm{Y}=\mathrm{a} \cdot \operatorname{mass}^{\mathrm{k}_{1}} \cdot \text { height }^{\mathrm{k}_{2}} \cdot \varepsilon
$$

The model has the advantage of having proportional body-size components and a multiplicative error that assumes, $\varepsilon$, will increase proportionally with the physical performance variable Y (see Fig. 1).

$$
\text { ****Figure } 1 \text { near here**** }
$$

The model (Eq. 1) can be expanded to incorporate FM\% and SAR as follows;

$$
\mathrm{Y}=\mathrm{a} \cdot \operatorname{mass}^{\mathrm{k}_{1}} \cdot \text { height }^{\mathrm{k}_{2}} \cdot \mathrm{FM} \%{ }^{\mathrm{k}_{3}} \cdot \exp (\mathrm{b} \cdot \mathrm{FM} \%+\mathrm{c} \cdot \mathrm{SAR}) \cdot \varepsilon .
$$

There are considerable advantages in incorporating FM\% in the multiplicative model (Eq. 2) as both a proportional allometric term $\left(\mathrm{FM}^{\mathrm{k}_{3}}\right)$ as well as within the exponential function (see Nevill and Holder, 1999). By doing so, the terms provide a form of 'gamma function' within the model that is able to describe an initial growth in physical performance with FM\% (associated with overly thin children) as a proportional or allometric term that will peak but then slowly decline with excessive FM\% (as a negative exponential term)

The models (Eqs. 1 and 2) can be linearized with a log transformation. A linear regression analysis on $\log (\mathrm{Y})$ can then be used to estimate the unknown parameters of the log transformed models:

$$
\log (\mathrm{Y})=\log (\mathrm{a})+\mathrm{k}_{1} \cdot \log (\text { height })+\mathrm{k}_{2} \cdot \log (\text { mass })+\log (\varepsilon)
$$$$
\left.\log (\mathrm{Y})=\log (\mathrm{a})+\mathrm{k}_{1} \cdot \log (\text { height })+\mathrm{k}_{2} \cdot \log (\text { mass })\right)+\mathrm{k}_{3} \cdot \log (\mathrm{FM} \%)+\cdot \mathrm{b} \cdot \mathrm{FM} \%+\mathrm{c} \cdot \mathrm{SAR}+\log (\varepsilon)
$$ 
Further categorical or group differences within the population, e.g. sex, age (entered as discrete categories, 11 to 14 years old) and place of residence (urban vs. rural) can be explored by allowing the constant intercept parameter ' $\log (\mathrm{a})$ ' to vary for each group by introducing them as fixed factors within an ANCOVA. The significance level was set at $P<0.05$. 


\section{RESULTS}

The mean (SD) physical fitness tests results by sex, age and place of residence are given in Table 2 .

****Table 2 near here*****

\section{Standing Broad Jump test}

The estimated allometric parameters from the two multiplicative models relating the SBJ distance to the body-size components in Eq.1, and the model Eq. 2 incorporating FM\% and SAR, are given in Table 3.

$* * * *$ Table 3 near here $* * * *$

The multiplicative model (Eq.1) relating the SBJ distance to the body-size components for SBJ was:

$$
\text { SBJ distance }(\mathrm{cm})=\mathrm{a} \cdot \text { mass }^{-0.357} \cdot \text { height }^{1.302}
$$

With a positive height and a negative mass exponent, the model suggest the optimal body-size height-tomass ratio associated with SBJ is approximately the reciprocal ponderal index $(\mathrm{RPI})=$ height $\cdot$ mass $^{-0.333}$.

Fitting Model (Eq.1) revealed significant differences in the constant 'a' parameter due to sex $(\mathrm{P}<0.001)$, age $(\mathrm{P}<0.001)$ and by place of residence (urban vs. rural) $(\mathrm{P}<0.05)$, together with two interactions between the categorical variables age and $\operatorname{sex}(\mathrm{P}<0.001$; Figure 2a) and age and place of residence $(\mathrm{P}<0.01$; Figure 2b).

$* * * *$ Figure $2 \mathrm{a}, 2 \mathrm{~b}$ near here $* * * *$

As soon as the terms FM\% and SAR terms were incorporated into Model (Eq.2) to predict SBJ distance, the dominance of the negative body-mass term was replaced by the more sensitive fat-mass (\%) terms, entered as a gamma function (compare the T-test scores in Table 3). The model predicts a small initial rise, but then an overall decline in SBJ with greater FM\%. Differential calculus reveals that peak SBJ occurs at FM\% $=-(0.158-0.072) /(-0.015)=5.7 \%$ in boys and FM\% $\%=-0.158 /(-0.015)=10.7 \%$ in girls based on the estimated gamma function terms from Table 3, see plots for boys and girls in Figure 3.

$* * * *$ Figure 3 near here**** 
Note that the sit-and-reach (SAR) test results are positively associated with log-transformed SBJ performance, see Table 3 .

The effect of incorporating FM\% and SAR into the Model (Eq.2) to predict SBJ distance revealed significant differences in the constant ' $\mathrm{a}$ ' parameter due to age $(\mathrm{P}<0.001)$ and place of residence (urban vs. rural $)(\mathrm{P}<0.05)$ BUT not sex $(\mathrm{P}>0.05)$. The two interactions remained as before but the gap between boys' and girls' Ln(SBJ) performances in the sex-by-age interaction was greatly reduced, see Figure $2 c$. The interaction between place of residence (urban vs. rural) and age on jump distance (log transformed) remained largely unchanged.

$* * * *$ Figure $2 \mathrm{c}$ near here $* * * *$

\section{Sit-Up test}

The estimated allometric parameters from the two models relating the number of SUP to the body-size components in Eq.1, and the model Eq. 2 incorporating FM\% and SAR, are given in Table 4.

$* * * *$ Table 4 near here $* * * *$

The multiplicative model relating the number of sit-ups performed in $30 \mathrm{~s}$ (SUP) to the body-size components identified the mass and height exponents as $\mathrm{k}_{1}=-0.307$ ( $\left.\mathrm{SEE}=0.019\right)$ and $\mathrm{k}_{2}=0.958$ $(\mathrm{SEE}=0.081)$ respectively. The body-mass and height components associated with the model (Eq.1) for the number of sit-ups in $30 \mathrm{~s}$ can be rearranged and expressed as a height-to-mass ratio within a curvilinear power function as follows;

$$
\operatorname{mass}^{-0.307} \cdot \text { height }^{0.958}=\left(\text { height } \cdot \operatorname{mass}^{-0.320}\right)^{0.958}
$$

since mass ${ }^{-0.307}=\left(\text { mass }^{-0.320}\right)^{0.958}$. The $95 \%$ confidence interval $(\mathrm{CI})$ for the rearranged/rescaled mass exponent -0.320 is $(-0.358$ to -0.282$)$. Note that this height-to-body mass ratio is very similar to the reciprocal ponderal index $(\mathrm{RPI})=$ height $\cdot \operatorname{mass}^{-0.333}$, since the $95 \% \mathrm{CI}$ encompasses -0.333 .

When we fitted Model (Eq.1) to the log-transformed SUP, the constant 'a' parameter varied by sex $(\mathrm{P}<0.001)$, age $(\mathrm{P}<0.001)$ and by place of residence (urban vs. rural) $(\mathrm{P}<0.001)$ together with two 
interactions between the categorical variables age and sex $(\mathrm{P}<0.001$; Figure $4 \mathrm{a})$ and age and place of residence $(\mathrm{P}<0.05$; Figure $4 \mathrm{~b})$.

$* * * *$ Figure $4 \mathrm{a}, 4 \mathrm{~b}$ near here $* * * *$

As soon as the terms FM\% and SAR terms were incorporated into Model (Eq.2) to predict the number of SUP distance-(see Table 4), once again the dominance of the negative body-mass term was replaced by the more sensitive fat-mass (\%) terms, entered as a gamma function (compare the T-test scores in Table 4). As with the LnSBJ model, the model for LnSUP predicts a small initial rise, but then an overall decline in SUP with greater FM\%. Differential calculus reveals that peak in SUP occurs at FM\%=$(0.263-0.139) /(-0.018)=6.8 \%$ in boys and FM\% $=-(0.263) /(-0.018)=14.4 \%$ in girls based on the estimated gamma function terms from Table 4.

The sit-and-reach (SAR) results were again positively associated with log-transformed SUP performances, see Table 4.

The effect of incorporating FM\% and SAR into the Model (Eq.2) to predict the number of SUP revealed significant differences in the constant 'a' parameter due to age $(\mathrm{P}<0.001)$, sex $(\mathrm{P}<0.001)$ and place of residence (urban vs. rural) $(\mathrm{P}<0.05)$. Only the sex-by-age interactions remained but, as with the sex-byage interaction with SBJ, the gap between the boys and girls was greatly reduced, see Figure 4c.

$* * * *$ Figure $4 \mathrm{c}$ near here $* * * *$

\section{DISCUSSION}

The initial findings of the current study identified differences in children's strength outcomes due to sex, age and habitat (urban versus rural) having controlled for differences in body size (height and body mass) using allometry. The allometric model (Eq. 1) identified the optimal height-to-body mass ratios associated with the standing broad jump and sit-ups in 30 seconds to be (height $\cdot$ mass $\left.^{-0.357}\right)^{1.302}$ and (height. mass ${ }^{-}$ $\left.{ }^{0.320}\right)^{0.958}$ respectively. With a positive height and a negative mass exponent (being approximately $-1 / 3$ ), these models indicate the optimal body-size or height-to-mass ratio associated with SBJ and SUP is approximately the reciprocal ponderal index $(\mathrm{RPI})=$ height $\cdot \operatorname{mass}^{-0.333}$. The RPI suggests that taller, more 
linear or ectomorphic children (W. H. Sheldon's classification of body types that measures the body's degree of slenderness and angularity) will perform better at such physical fitness tests.

Previous authors have reported similar findings with a variety of physical performance outcomes including dynamic muscle strength (Bustamante Valdivia et al., 2015; Markovic, 2004; Nevill et al., 2009; Silva et al., 2016) and general motor skills (Dos Santos et al., 2018). The negative effect of body mass in the RPI when predicting both SBJ and SUP is obvious (i.e., the power-weight ratio), but the positive relationship between height and performance is not so clear, although an increase in height in children and adolescent is often accompanied by an increase in muscle strength (Lieber, 2010) and therefore in power output.

Our initial findings indicate that more linear and ectomorphic children will perform better at physical performance tasks such as SBJ and SUP. However, being too lean might also be detrimental to physical performance. For this reason, we introduced FM\% as an additional predictor of the physical performance variables (Eq.2), entered as a gamma function. We also added the sit-and-reach (SAR) results to explore whether being more flexible might also benefited the children's performances.

The results reported for the model (Eq.2) in Tables 3 and 4 confirm our thoughts. The dominant (negative) body-mass term used in model (Eq. 1) was replaced by the more sensitive fat-mass (FM\%) terms, entered as a gamma function (for the relative importance, see the T-test scores in Tables 3 and 4). The model predicts a small initial rise, but then an overall decline in both SBJ and SUP with increasing FM\%. The peak in SBJ occurs at FM\%=5.7\% in boys and FM\%=10.7\% in girls, whilst the peak in SUP occurs at $\mathrm{FM} \%=6.8 \%$ in boys and $\mathrm{FM} \%=14.4 \%$ in girls (based on the estimated gamma function terms from Tables 3 and 4 respectively) The nature of the gamma-function curves can be seen in Figure 3 .

Being flexible also appears to benefit children's SBJ and SUP performances. Tables 3 and 4 reveal that for every $10 \mathrm{~cm}$ increase in SAR, the SBJ and SUP performances increased by $3 \%$ (T-test score $=15.5$ ) and $4.6 \%$ (T-test score-12.9) respectively. The finding that flexibility is positively associated with physical performance tests is a novel insight although an article by García-Pinillos et al. (2015) did find evidence that greater hamstring flexibility benefitted a number of physical performance tests including vertical jump performance in semi-professional academy footballers. In their discussion the authors argue that "a muscle with greater length shows a higher rate of shortening and, consequently, a stiffer musculotendinous unit. This may facilitate performance by improving the force production capabilities of the contractile component and by enhancing initial force transmission. We therefore 
hypothesised that players with poor HF would show a lower performance on explosive tasks than players with better flexibility". Whether being flexible leads to better strength performances or whether superior strength outcomes result in greater flexibility is unclear and must be considered a limitation of our cross-sectional study. Nevertheless, it is an intriguing finding and one that provides a valuable opportunity for future research.

Significant differences in the $\operatorname{Ln}(\mathrm{SBJ})$ and $\operatorname{Ln}(\mathrm{SUP})$, due to sex and age having controlled for differences in height and body mass (Eq.1), can be seen clearly in Figure 2a and 4a. Boys outperformed girls in both tasks, a gap that increased with age, a finding that will almost certainly be explained by the children, in particular the boys, going through puberty at this age (11 to 14 years).

Overall, urban children outperformed their rural counterparts in both $\operatorname{Ln}(\mathrm{SBJ})$ (Tab 2b) and $\operatorname{Ln}(\mathrm{SUP})$ (Tab 4b), having controlled for differences in body size (Eq.1). These results are supported by Zheng \& An (2015) who reported that, compared to their matched urban counterparts, rural residents are $8.1 \%$ $(\mathrm{p}<0.0001)$ more likely to be physically inactive in their leisure time and $5.8 \%(\mathrm{p}=0.005)$ less likely to live within 30-minute walking distance to the nearest exercise facility. Other factors that might help explain our findings include environment differences (Carlson et al., 2014; De Greeff et al., 2014; Jaworski, Zychowska \& Szopa, 2003; Malina, Zavaleta \& Little, 1987), social economic factor (Tomkinson, et al., 2007) and family tradition (Sauka et al., 2011) that play an important role in the active life style and sport adherence of urban people. There is also some evidence that young people living in rural communities are more likely to be sedentary (Plotnikoff et al., 2004).

The above differences (due to sex, age and location) remained similar when we applied the expended allometric model to include the FM\% and SAR terms (Eq.2). The effect of incorporating FM\% into the Model (Eq.2) to predict $\operatorname{Ln}(\mathrm{SBJ})$ and $\operatorname{Ln}(\mathrm{SUP})$ had the effect of reducing the gap between boys and girls performances, see Figure 2c and 4c. Given that girls have over 60\% more FM\% than boys (see Table 1), when FM\% is taken into account, the girls performances are similar. This reduced sex-difference effect can be seen in Figure 3. Clearly, in absolute terms the girls $\operatorname{Ln}(\mathrm{SBJ})$ are lower than the boys but because their performances are also offset to the right, the gamma function lines now overlap, suggesting that for the same FM\%, the boys and girls $\operatorname{Ln}(\mathrm{SBM})$ performances are similar.

In summary, initially our results suggest that the optimal shape associated with two mass-dependent physical activities is an ectomorph body shape (linear physique). However, when we incorporated the 
BF\% and SAR terms into the allometric model (Eq.2), new insights we obtained. Although having an ectomorph body shape (linear physique) appears advantageous overall, being too thin can be detrimental to these strength outcomes. Another novel insight was obtained when we incorporated the SAR test into the allometric model (Eq. 2). For these children aged 11 to 14, being flexible would appear to benefit their strength outcomes. Whether being flexible leads to better strength outcomes or whether superior strength results in greater flexibility is unclear, however this intriguing finding provides a valuable opportunity for future research. Finally, our results indicate that urban children aged 11 to 14 have superior strength outcomes compared with rural children, having controlled for differences in body size/shape, a finding that may be associated with rural environments having fewer exercise facilities compared with urban conurbations

\section{ACKNOWLEDGEMENTS}

The authors wish to thank the children/students for participating in the study. They also wish to thank Mark Lyons and Athalie Redwood-brown for their advise regarding the relationship between flexibility and strength outcomes/performances.

\section{References}

1. Ainsworth B. E., Haskell, W. L., Whitt, M. C., Irwin, M. L., Swartz, A. M., Strath, S. J., ... Leon, A. S., (2000). Compendium of physical activities: an update of activity codes and MET intensities. Medicine \& Science in Sports \& Exercise 32(suppl): S498-S516.

2. Artero, E. G., España-Romero, V., Castro-Piñero, J., Ortega, F.B., Suni. J., Castillo-Garzon. M. J., \& Ruiz. J. R. (2011). Reliability of field-based fitness tests in youth. International Journal of Sports Medicine; 32(3):159-69.

3. Bjerregaard, L. G., Rasmussen, K. M., Michaelsen, K. F., Skytthe. A., Mortensen, E. L., Baker, J. L., \& Sørensen, T. I. (2014). Effects of body size and change in body size from infancy through childhood on body mass index in adulthood. International journal of obesity : journal of the International Association for the Study of Obesity, 38(10):1305-11

4. Blaha, P., Vignerova, J. (2002). Investigation of the growth of Czech children and adolescents: Normal, underweight, overweight. Prague: National Institute of Public Health; 130 p.17

5. Boeke, C. E., Oken, E., Kleinman, K. P., Rifas-Shiman, S. L., Taveras, E. M., Gillman, M. W. (1993). Correlations among adiposity measures in school-aged children. BMC pediatrics; 13:99. 
6. Bouchard, C., Shephard, R. J., \& Stephens, T. H. (1993). Physical Activity, Fitness and Health. A Consensus of Current Knowledge. Champaign. IL: Human Kinetics

7. Bozic, P. R., Pazin, N. R., Berjan, B. B., Planic, N. M., Cuk, I. D. (2010). Evaluation of the field tests of flexibility of the lower extremity: reliability and the concurrent and factorial validity. Journal of strength and conditioning research, 24(9): 2523-31

8. Bustamante Valdivia, A., Maia, J., \& Nevill, A. (2015). Identifying the ideal body size and shape characteristics associated with children's physical performance tests in Peru. Scandinavian journal of medicine \& science in sports, 25(2):e155-65.

9. $\quad$ Carlson, J. A., Sallis, J. F., Kerr, J., Conway, T. L., Cain, K., Frank, L. D., \& Saelens, B. E. (2014). Built environment characteristics and parent active transportation are associated with active travel to school in youth age 12-15. British Journal of Sports Medicine, 48, 1634-1639.

10. Carter, J. E. L. (2002). The Heath-Carter anthropometric somatotype. Instruction manual. San Diego: San Diego State University; p. 26

11. Castro-Piñero, J., Artero, E. G., España-Romero, V., Ortega, F. B., Sjöström, M., Suni, J., \& Ruiz J. R. (2010). Criterion-related validity of field-based fitness tests in youth: a systematic review. British journal of sports medicine, 44(13):934-43.

12. C.I.A. (2011). Theworldfactbook. Retrieved November. 2017 from http://www.cia.gov/cia/publications/factbook/index.html.

13. Clarys, J. P., Provyn, S., Marfell-Jones, M., \& Van Roy, P. (2006). Morphological and constitutional comparison of age-matched in-vivo and post-mortem populations. Morphologie, 90(291):189-96.

14. Cole, T. J., Bellizzi, M. C., Flegal, K. M., \& Dietz, W. H. (2000). Establishing a standard definition for child overweight and obesity worldwide: international survey. BMJ : British medical journal, 330: 1240-1244.

15. Cole, T. J., Flegal, K. M., Nicholls, D., \& Jackson, A. A. (2007). Body mass index cut offs to define thinness in chidren and adolescents: international survey. BMJ : British medical journal, 335: 194-197.

16. Collins, P., Al-Nakeeb, Y., Nevill, A., \& Lyons, M. (2012). The impact of the built environment on young people's physical activity patterns: a suburban-rural comparison using gps. International Journal of Environmental Research and Public Health, 9(9), 3030-3050. 
17. Council of Europe (1998). Eurofit: handbook for the eurofit tests of physical fitness. Secretariat of the committee for the development of sport within the council of Europe, Rome, Italy.

18. Deforche, B., Lefevre, J., Bourdeaudhuij, I. D., Hills, A. P., Duquet, W., \& Bouckaert, J. (2003). Physical Fitness and Physical Activity in Obese and Nonobese Flemish Youth. Obesity Research, 11: 434-41.

19. De Greeff, J. W., Hartman, E., Mullender-Wijnsma, M. J., Bosker, R. J., Doolaard, S., \& Visscher, C. (2014). Physical fitness and academic performance in primary school children with and without a social disadvantage. HEALTH EDUCATION RESEARCH, 29: 5. 853-860

20. Dos Santos, M. A. M., Nevill, A. M., Buranarugsa, R., Pereira, S., Ferreira Gomes, T. N. Q., Reyes, A., ... Maia, J. A. R. (2018). Modeling children's development in gross motor coordination reveals key modifiable determinants. An Allometric approach. Scandinavian journal of medicine \& science in sports, 28(5):1594-1603.

21. Duren, D. L., Sherwood, R. J, Czerwinski, S. A., Lee, M., Choh, A. C., Siervogel, R. M., Cameron Chumlea, W. (2008). Body composition methods: comparisons and interpretation. Journal of diabetes science and technology, 2:1139-1146.

22. García-Pinillos, F., Ruiz-Ariza, A., Moreno del Castillo, R., \& Latorre-Román, P. Á. (2015). Impact of limited hamstring flexibility on vertical jump, kicking speed, sprint, and agility in young football players. Journal of sports sciences, 33(12), 1293-1297.

23. Heymsfield, S. B., Lohmann, T., Wang, Z., Going, S. B. (2005). Human Body Composition, Champaign, Human Kinetics Press

24. Huotari, P. R., Nupponen, H., Laakso, L., \& Kujala, U. M. (2010). Secular trends in aerobic fitness performance in 13-18-year-old adolescents from 1976 to 2001. British journal of sports medicine, 44(13):968-72.

25. Huttunen, N. P., Knip, M., \& Paavilainen, T. (1986). Physical activity and fitness in obese children. International journal of obesity, 10(6):519-25.

26. Jaworski, J., Zychowska, M., \& Szopa, J. (2003). Functional involution in rural areas of south Poland - preliminary report. Journal of Human Kinetics, 10, 77-84

27. Kemper, H. C. G., \& Van Mechelen, W. (1996). Physical fitness testing of children: a european perspective. Pediatric exercise science, 8: 201-214.

28. Lieber, R. L. (2010). Skeletal muscle structure, function and plasticity. 3rd edition. Lippincott Williams \&Wilkins, Baltimore: (MD). 
29. Lloyd, R. S., Oliver. J. L., Faigenbaum, A. D., Myer, G. D., \& De Ste Croix, M. B. (2014). Chronological age vs. biological maturation: implications for exercise programming in youth. Journal of strength and conditioning research, 28(5):1454-64, Review.

30. Lovecchio, N., Casolo, F., Invernizzi, P. L., \& Eid, L. (2012). Strenght in young italian students: results from eurofit test and comparison among european data. Polish Journal of Sport and Tourisme, 5 (19): 13-15

31. Lovecchio, N., Novak, D., Eid, L., Casolo, F., \& Podnar, H. (2015). Urban and rural fitness level: comparison between italian and croatian students. Perceptual \& Motor Skills, 120, 2, $367-$ 380.

32. Lovecchio, N., \& Zago, M. (2018-in press). Fitness differences according to BMI categories: a new point of view. Journal of Sport Medicine and Physical Fitness

33. Malina, R. M., Zavaleta, A. N., \& Little, B. B. (1987). Body Size, Fatness, and Leanness of Mexican American Children in Brownsville. Texas: Changes between 1972 and 1983. American Jouranl of Public Health, 77, 5; 573-577

34. Malina, R. M., Peña Reyes, M. E., \& Little, B. B. (2008). Secular change in the growth status of urban and rural schoolchildren aged 6-13 years in Oaxaca. Southern Mexico. Annals of Human Biology, 35, 475-489

35. Markovic, G. (2007). Does plyometric training improve vertical jump height? A meta-analytical review. British journal of sports medicine, 41: 349-355.

36. Nevill, A., Tsiotra, G., Tsimeas, P., \& Koutedakis, Y. (2009). Allometric associations between body size, shape, and physical performance of greek children. Pediatric Exercise Science, 21(2):220-32.

37. Nevill, A. M., \& Holder, R. L. (1995). Scaling, normalizing, and per ratio standards: an allometric modeling approach. Journal of applied physiology, 79(3):1027-31.

38. Nevill, A. M., \& Holder, R. L. (1999). Identifying population differences in lung function: results from the Allied Dunbar national fitness survey. Annals of Human Biology, 26, 267-285.

39. Nevill, A. M., \& Holder, R. L. (2000). Modelling health-related performance indices. Annals of Human Biology, 27(6):543-59.

40. Ortega, F. B., Artero, E. G., Ruiz, J. R., Vicente-Rodriguez, G., Bergman, P., Hagströmer, M., ... \& HELENA Study Group. (2008). Reliability of health-related physical fitness tests in European 
adolescents. The HELENA Study. International journal of obesity : journal of the International Association for the Study of Obesity, 32 Suppl 5:S49-57.

41. Plotnikoff, R. C., Bercovitz, K., \& Loucaides, C. A. (2004). Physical activity, smoking, and obesity among Canadian school youth: comparison between urban and rural schools. Canadian Journal of Public Health, 95, 413-418.

42. Pokos, N. (2002). Mmetodologija izdvajanja seoskog stanovništva, njegov raspored i popisne promjene 1953-2001 [methodology of allocations of the rural population, its distribution and inventory changes]. In Štambuk, M., Rogić, I., Mišetić, A. (eds.). Prostor iza: kako modernizacija mijenja hrvatsko selo [The area behind: how modernization changes the croatian village]. Zagreb, Croatia: Institut društvenih znanosti ivo pilar.

43. Ruiz, J. R., Castro-Piñero, J., España-Romero, V., Artero. E. G., Ortega, F. B., Cuenca, M. M., ... \& Castillo, M. J. (2011). Field-based fitness assessment in young people: the ALPHA healthrelated fitness test battery for children and adolescents. British journal of sports medicine, 45(6):518-24.

44. Sauka, M., Priedite, I. S., Artjuhova, L., Larins, V., Selga, G., Dahlström, Ö., \& Timpka, T. (2011). Physical fitness in northern European youth: reference values from the Latvian Physical Health in Youth Study. Scandinavian Journal of Public Health, 391, 35-43.

45. Seefeldt, V., Malina, R. M., \& Clark, M. A. (2002). Factors affecting levels of physical activity in adults. Sports Medicine, 33. 143-168.

46. Silva, S., Bustamante, A., Nevill, A., Katzmarzyk, P. T., Freitas, D., Prista, A., \& Maia, J. (2016). An Allometric Modelling Approach to Identify the Optimal Body Shape Associated with, and Differences between Brazilian and Peruvian Youth Motor Performance. PLoS One, 3;11(3):e0149493

47. Smith, J. D., Montaño, Z., Dishion, T. J., Shaw, D. S., \& Wilson, M. N. (2015). Preventing weight gain and obesity: indirect effects of the family check-up in early childhood. Prevention science: the official journal of the Society for Prevention Research, 16(3):408-19

48. Tomkinson, G. R., Olds, T. S., \& Borms, J. (2007). Who are the Eurofittest? Medicine and sport science, 50:104-28.

49. Tomkinson, G. R., Carver, K. D., Atkinson, F., Daniell, N. D., Lewis, L. K., Fitzgerald, J. S., ... Ortega, F. B. (2017). European normative values for physical fitness in children and adolescents aged 9-17 years: results from 2779165 Eurofit performances representing 30 countries. 
50. British journal of sports medicine, 52(22):1445-14563

51. Tsimeas, P. D., Tsiokanos, A. L., Koutedakis, Y., Tsigilis, N., \& Kellis, S. (2005). Does living in urban or rural settings affect aspects of physical fitness in children? An allometric approach. British Journal of Sports Medicine, 39(9):671-4.

52. United Nations. (2002). World urbanization prospects: the 2001 revision. New York: United Nations

53. Vandorpe, B., Vandendriessche, J., Lefevre, J., Pion, J., Vaeyens, R., Matthys, S., .... Lenoir, M. (2011). The KörperkoordinationsTest für Kinder: reference values and suitability for 6-12-yearold children in Flanders. Scandinavian journal of medicine \& science in sports, 21(3):378-88.

54. Zheng, J., \& An, R. (2015). Satisfaction with local exercise facility: a rural-urban comparison in China. Rural Remote Health, 15(1):2990. 